\title{
Experiências com a gestão autônoma da medicação: narrativa de usuários de saúde mental no encontro dos grupos focais em centros de atenção psicossocial
}

\author{
I ${ }^{1}$ Maria Salete Bessa Jorge, ${ }^{2}$ Rosana Onocko Campos, \\ ${ }^{3}$ Antonio Germane Alves Pinto, ${ }^{4}$ Mardênia Gomes Ferreira Vasconcelos I
}

Resumo: Objetiva-se analisar as experiências vivenciadas pelos usuários do Centro de Atenção Psicossocial no desenvolvimento do grupo para Gestão Autônoma da Medicação (GAM). Opta-se pela pesquisa qualitativa, dentro de uma perspectiva crítica que protagoniza a vivência dos participantes do grupo operativo GAM. Realizado nos Centros de Atenção Psicossocial (CAPS) Geral e Álcool e outras Drogas (AD) do município de Maracanaú-CE. Os participantes foram 13 usuários de CAPS Geral e Ad do referido município. Técnica de coleta das narrativas foi constituída por três grupos narrativos e a análise pautada na hermenêutica. Segundo as narrativas desvelaram, em todo o processo de discussão sobre a medicação, fica evidente a importância da escuta e do acompanhamento individual. A abordagem singular dos usuários possibilitou melhoria significativa no estado de saúde mental e na compreensão do adoecimento. Assim, é possível ressignificar a utilização precípua do medicamento e interagir com inovaçôes terapêuticas mais voltadas para hábitos de vida saudável.

> Palavras-chave: saúde mental; centro de atenção psicossocial; gestão autônoma da medicação

\author{
1 Doutora em Enfermagem \\ pela Universidade de São \\ Paulo; professora titular da \\ Universidade Estadual do Ceará \\ (UECE). Endereço eletrônico: \\ maria.salete.jorge@gmail.com \\ 2 Doutora em Saúde Coletiva; \\ coordenadora e docente do \\ Programa de Saúde Coletiva da \\ UNICAMP. Endereço eletrônico: \\ rosanaoc@mpc.com.br \\ ${ }^{3}$ Enfermeiro. Doutorando \\ em Saúde Coletiva (UECE); \\ professor assistente da \\ Universidade Regional do Cariri \\ (URCA). Endereço eletrônico: \\ germanepinto@hotmail.com \\ ${ }^{4}$ Enfermeira. Doutoranda \\ em Saúde Coletiva (UECE). \\ Endereço eletrônico: \\ mardeniagomes@yahoo.com.br
}

Recebido em: 24/04/2012. Aprovado em: 22/11/2012. 


\section{Introdução}

O objeto de estudo pauta-se na análise das experiências vivenciadas pelos usuários do Centro de Atenção Psicossocial (CAPS) no desenvolvimento do grupo operativo para Gestão Autônoma da Medicação (GAM). Enfatizaramse o processo terapêutico empreendido e sua interlocução com os sentidos e significados do tratamento medicamentoso, a interação com a equipe de saúde mental, família e comunidade, bem como a resolubilidade assistencial.

A experiência em desenvolver o grupo GAM faz parte da iniciativa de pesquisa implementada no Brasil na Universidade de Campinas (UNICAMP) e Associação de Familiares e Amigos da Saúde Mental de Campinas (Aflore), pelo Projeto ARUC (Associação Internacional de Pesquisa Universidade-Comunidade, em parceria Brasil-Canadá), reunindo quatro universidades brasileiras (UNICAMP, UFF, UFRJ e UFRGS). Posteriormente, o Ceará integrou essa parceria, por meio de um projeto de pesquisa.

A autonomia, ainda que como um vir-a-ser, merece ser resgatada conceitualmente como uma condição de saúde e cidadania, da própria vida, um valor fundamental, portanto, mas que não é, nem pode ser absoluta. É relativa e relacional, como mencionado, e deve ser construída em um processo de produção contínua numa rede de dependências bastante maleável e que necessariamente se vê reduzida no adoecimento. Entretanto, ela deve ser construída de modo continuado em sua inter-relação com a dependência no cotidiano da prática (SOARES; CAMARGO JR., 2007).

O GAM constitui uma proposta participativa de discussão e reflexão sobre o uso de medicamentos psicotrópicos, com a finalidade de disparar autoconhecimento e autonomia e buscar o diálogo no sentido de reduzi-los, a fim de construir experiências significativas em sua vida social e individual.

Nas experiências individuais compartilhadas num coletivo grupal, emergem práticas cogestivas entre usuários e profissionais de saúde na condução terapêutica. Logo, o processo grupal sobressai a dimensão celibatária da comunhão dos iguais. $\mathrm{Na}$ grupalidade, pressupõe-se o respeito das afetaçōes recíprocas, de maneira mais múltipla, centrada, calcada sobretudo no jogo entre as singularidades e o comum, e na potência ampliada da composição - sempre levando em conta o plano de consistência. Ao mesmo tempo, singularidade, individualidades e coletivo (PELBART, 2011). 
Cabe ressaltar que as experiências individuais partilhadas são expostas através de uma narrativa que, por meio da linguagem, trazendo à tona um modo de ser-no-mundo e de habitar nesse mundo (RICOUER, 1991). Assim, essa experiência vivida do sujeito, essa maneira de ser é expressa e trazida ao coletivo, e nele poderá ser processada, reelaborada e transformada. No entanto, o mundo contemporâneo apresenta uma complexidade de problemas, os quais também envolvem o adoecimento humano. As doenças psíquicas absorvem as modificações urbanas, sociais e cotidianas e o enfrentamento do ser humano perante tal disfunção sucumbe à utilização de práticas unívocas baseadas somente em poçōes fármaco-terápicas.

Referida hegemonia vem sendo construída na subordinação da prática clínica como dimensão social e humana da vida a uma tecnologia biopolítica de gestão da vida, concebida no biopoder, e também entendida como medicalização social que se mostra compatível e aceita na própria matriz da ciência moderna. Desse modo, conformam-se práticas clínicas na sociedade que priorizam elementos de intervenção voltados para a elucidação diagnóstica orgânica, terapêuticas medicalizantes e prioritariamente fármaco-químicas, bem como abordagens unidirecionais em que o indivíduo ali tido como adoecido deve simplesmente adaptar-se ao processo de cuidar estabelecido (KOIFMAN, 2001; FERLA, 2004; MACIEL, 2007).

Nesse prisma, o modelo assistencial reformista está baseado na superação do isolamento e na vida plena em sociedade, e preconiza a concepção de transtorno, disfunção e/ou sofrimento psíquico como um estado ou período de evidenciação de sinais e sintomas específicos da mente, passíveis de intervenção terapêutica e de cooperação mútua (AMARANTE, 2000).

Historicamente, o movimento da Reforma Psiquiátrica coloca como desafio clínico-político a redefinição do sentido de autonomia para os usuários dos serviços substitutivos ao manicômio. Esse sentido de autonomia deve ampliar e mesmo alterar aquele advindo do projeto da modernidade, pois a autonomia não é mais pensada como estritamente do domínio do indivíduo. No campo da Reforma Psiquiátrica brasileira, considera-se o processo de autonomização e emancipação como sendo coletivo e compartilhado.

Ao pensar os valores e negociações do projeto terapêutico com foco no protagonismo do sujeito, direciona-se uma conduta voltada para a habilitação 
deste indivíduo, no sentido de interagir com o mundo ao seu redor. Os valores e princípios pessoais condensados na vivência social dinamizam o comportamento humano, a percepção sobre si mesmo e a inter-relação sócio-familiar. Como se afirma, a prática antimanicomial e a reabilitação psicossocial ampliam o espectro clínico para a dimensão subjetiva e assim delineiam o caminho essencial para efetivar suas ações (AMARANTE, 2007).

Contudo, o GAM deve ser entendido como um dispositivo que envolve o serviço de saúde mental como um todo em suas várias dimensões: da gestão, do cuidado, da ambiência. Consoante os resultados da pesquisa têm mostrado, a valorização da experiência dos usuários com ênfase nos seus direitos e autonomia indicou a dificuldade de inclusão dos diferentes sujeitos (usuários, trabalhadores e gestores) nas práticas de gestão da clínica. Nesta perspectiva, objetiva-se analisar as experiências dos usuários do CAPS no processo grupal voltado para Gestão Autônoma da Medicação com ênfase no tratamento farmacológico, intersubjetividades e resolubilidade assistencial.

\section{Metodologia}

Optou-se pela pesquisa qualitativa, dentro de uma perspectiva participativa, que protagoniza a vivência dos participantes do grupo operativo na Gestão Autônoma da Medicação, com ênfase nas experiências do usuário em suas relaçôes com a equipe de saúde, familiares e comunidade e a resolutividade na atenção psicossocial no Sistema Único de Saúde (SUS).

Compõe este escopo investigativo a proposição avaliativa de quarta geração. Nesta opção metodológica, admite-se a diversidade de olhares analisadores e interpretativos com a participação dos sujeitos envolvidos no estudo, possibilitando se apropriarem dos conhecimentos gerados na realização do processo avaliativo. Desse modo, viabilizam e ampliam a utilização dos resultados da avaliação (FURTADO, 2001).

A referida pesquisa foi desenvolvida no Estado do Ceará, especificamente no município de Maracanaú, junto aos Centros de Atenção Psicossocial Geral e Álcool e outras Drogas. O CAPS Geral deste município foi implantado em 2005, situando-se dentro da modalidade tipo II, prevista para municípios de 70.000 a 200.000 habitantes, com regime de funcionamento em dois turnos diurnos. Sua capacidade instalada preconiza o atendimento a 220 pacientes 
mensais, dos quais 45 pacientes intensivos, 75 semi-intensivos e 100 não-

intensivos. Já o CAPS AD de Maracanaú foi inaugurado em dezembro de 2008, e hoje possui pouco mais de 100 prontuários ativos.

Como participantes, incluíram-se 13 usuários dos CAPS Geral e AD. A amostra da pesquisa compõe o desenvolvimento do grupo GAM formado por usuários de psicofármacos há pelo menos um ano, profissionais de saúde mental, além dos facilitadores-pesquisadores.

A técnica de coleta dos dados foi o grupo focal e o grupo narrativo (GN) (ONOCKO-CAMPOS et al., 2008), mais apropriada para o estudo por se tratar de pesquisa qualitativa participativa de quarta geração com destaque para a experiência dos participantes. Para compreensão do leitor, o grupo narrativo consiste em construir uma narrativa única do grupo focal a cada sete sessões e retornar ao grupo de usuários com a finalidade de refletir e validar seus pensamentos na narrativa e assim refletir sobre os acontecimentos.

Grupos narrativos foram realizados durante o processo operacional do grupo GAM em três momentos distintos. Ao final de 21 encontros, o grupo GAM foi desenvolvido por seis meses, com um encontro por semana. A cada sete encontros, elaborou-se uma narrativa baseada nas informações obtidas a partir da função de coleta de dados dos três facilitadores (manejador, observador e anotador). No oitavo encontro, a narrativa foi devolvida aos participantes do grupo GAM, registrando-se as apreciaçōes deles a respeito das mesmas. Desse modo, a tarefa da pesquisa passou a acompanhar o processo de emergência do mundo na experiência dos usuários e trabalhadores de saúde mental no grupo, num processo de avaliação dos efeitos da própria experiência.

Essa mútua implicação confere à pesquisa um caráter de intervenção e seu aspecto de cuidado. Cuidar é assumir o protagonismo dos participantes da pesquisa, tomá-los menos como "algo à frente" sobre o qual se constrói um ponto de vista privilegiado em que há no encontro expressões de experiências que os levam a refletir em busca de novos horizontes.

A análise das narrativas está pautada na proposição metodológica e analítica fundamentada na hermenêutica. Em detalhe, propõem-se como síntese deste método os passos descritos para interpretação dos resultados em dois níveis: das determinações fundamentais e do encontro com os fatos empíricos. Segundo previsto, o processo de evidenciação das sínteses foi discutido entre 
os participantes, implementado a partir de olhares e experiências dos sujeitos envolvidos e articulado com a literatura disponível na área de conhecimento.

De acordo com o determinado, cumpriram-se os preceitos éticos da pesquisa envolvendo seres humanos, segundo o Comitê de Ética em Pesquisa da Universidade Estadual do Ceará (UECE), sob o parecer nº 11221983-7.

\section{Resultados: o olhar dos usuários sobre o GAM Ressignificação do tratamento psiquiátrico}

A síntese narrativa apresenta o cotidiano de vida social dos usuários atendidos no CAPS e sua interlocução com os profissionais. Nesse caso, a condução terapêutica é relatada na ótica de quem está sendo assistido pelo serviço de saúde mental. É possível apreender práticas e vivências da relação social após o ingresso no tratamento, reconhecendo o significado do medicamento e do equilíbrio psíquico-emocional.

$\mathrm{Na}$ tentativa de cumprir a premissa da atenção psicossocial, os CAPS disponibilizam diversos dispositivos para reflexão, discussão e implantação estratégica de interlocuções sociais entre usuários, familiar, equipe de saúde e sociedade como um todo. No entanto, a vivência do usuário emite os valores e percepções envolvidas nessa interação social cotidiana.

De modo geral, a confiança recebida pelas pessoas com as quais o usuário convive é bem diferente do que se pensa nas intenções terapêuticas. Como evidenciado, até mesmo o núcleo familiar tende a diminuir o grau de confiabilidade no usuário por motivos ligados ao seu adoecimento. Frequentemente, o processo de inversão desta situação se inicia em casa. Os usuários procuram demonstrar suas necessidades pessoais, bem como suas dificuldades, no sentido de obter apoio e ajuda dos próprios familiares.

Pelo exposto, a organização das práticas de saúde e o campo relacional na produção do cuidado com ênfase nas tecnologias leves possibilitam a forma efetiva e criativa de manifestação da subjetividade do outro, a partir dos dispositivos de acolhimento, vínculo e responsabilização contidos nessa organização da assistência à saúde (AYRES, 2004).

Em comunidade, os vizinhos estão presentes na primeira linha de interação social. Com eles, podem se estabelecer laços de amizade solidária e conseguir demonstrar que os problemas enfrentados pelo usuário do CAPS são também 
vivenciados por eles diariamente. Sendo assim, ao ajudar a diminuir o estresse e o

sofrimento daquele que já busca um tratamento especializado, surge também uma forma de perceber caminhos para a própria saúde mental.

Algumas pessoas, e, em alguns casos, até a família deixam de acreditar na gente por causa do tratamento. Isso é um problema para todos nós porque atrapalha nas atividades do dia-a-dia. A falta de confiança das pessoas na gente é um problema. Hoje, estou conseguindo recuperar a confiança da minha mãe, dos filhos e da esposa. Ficam próximos de nós, a família, os amigos e os profissionais do CAPS. E assim, nossos parentes nos ajudam por verem a necessidade que temos em viver melhor. Os vizinhos também ajudam e ao mesmo tempo são ajudados com nossas experiências. É assim, quando ajudamos o outro, também nos ajudamos em se sentir melhor. (Narrativa de usuários do grupo GAM).

Entidades comunitárias, dispositivos assistenciais, associações voltadas para redução do uso problemático de álcool e outras drogas e as igrejas são citadas como espaços para troca de experiência, estímulo à mudança pessoal e formação de vínculos entre pessoas interessadas em melhorar a saúde mental.

Um caminho para a liberdade é o trabalho. Inegavelmente, o sentimento de utilidade social, ou seja, a sensação de estar fazendo algo que pode contribuir com a própria sustentação financeira, revela-se como importante mecanismo de alcance da autonomia e liberdade.

Tem também os grupos de ajuda na comunidade, tais como, os alcoólicos anônimos, narcoticos anônimos e os grupos de oração. Os serviços que fazemos, ou seja, as coisas que a gente faz trabalhando também ajudam para que nos sintamos melhor. A poesia e a música são ótimas para viver melhor. (Narrativa de usuários do grupo GAM).

As necessidades de saúde inseridas na concepção central da prática do cuidado a ser efetivado são capazes de ampliar a definição de integralidade assumida nos serviços. Perceber tais necessidades evidencia a potencialidade dos trabalhadores, equipe, serviços e redes de fazer a melhor escuta das pessoas que buscam o atendimento (CECÍLIO, 2006).

No dia a dia, as relações pessoais mais próximas, isto é, a ligação com a família nuclear (pais, esposas e filhos), melhoram com a continuidade do tratamento recebido. Portanto, o estabelecimento do equilíbrio mental proporciona uma convivência mais agradável para quem está perto. São citadas situações de instabilidade, de descontrole e até de alteração do estado mental como pontos negativos para uma relação com bons vínculos entre os familiares. 
Pelo visto, as relações sociais se integram ao processo terapêutico como indicador da condição adequada do usuário em manter seu equilíbrio psíquico. Os efeitos do sofrimento e do próprio transtorno mental são remetidos à causalidade determinada pela vida contemporânea. Quando se apresenta afetado, o tratamento está mais ligado aos enfrentamentos estressores do que aos efeitos medicamentosos.

Em relação aos relacionamentos, quando a gente está bem, sem beber, p.ex., a gente conversa menos com as pessoas no geral, ou seja, a gente não conversa mais com todo mundo, mas com os conhecidos a gente passa a gostar mais, brincar, abraçar etc. É boa a sensação de bem-estar quando estamos próximos das pessoas. Os relacionamentos melhoram porque a outra pessoa vai gostar muito de dormir com alguém que não vai passar a noite acordado, nervoso de dia, ou seja, se a gente não dormir, o relacionamento piora porque a gente vai chatear outras pessoas. Quando se toma o remédio, normalmente, aumenta os vínculos com as outras pessoas. Isso acontece porque, algumas vezes, a gente sonha e vê pessoas conversando com a gente, na geladeira, mas com o remédio isso para de acontecer. A minha ansiedade não é nem pelo efeito dos remédios, é pelas coisas da vida mesmo. Não existe uma pílula mágica para resolver todos os problemas da vida. Nem sempre o médico precisa prescrever um medicamento, às vezes sim, às vezes não. Sair sem uma receita do consultório não quer dizer que o médico é ruim. (Narrativa de usuários do grupo GAM).

Assim, os usuários ressignificam o valor do medicamento em seus tratamentos. Admite-se a importância destes na redução da sintomatologia de cada episódio ou conjunto sindrômico inerente à patologia, mas se reconhece a necessária coexistência de outros dispositivos terapêuticos nesse processo.

O medicamento é apenas um auxílio para resolver os enfrentamentos difíceis da vida. Sozinho ele pode até prejudicar, em alguns casos, como nas situações de dependência ao medicamento. Percebemos muitas coisas no tratamento, e como podemos ser loucos, se entendemos o que acontece, o que se lê e o que se faz com a gente? A minha vida é igual a um pião. Tem vezes que estou igual a um esqueleto, dormindo numa rede, caído. Depois eu melhoro e fico bem como estou aqui no CAPS. Mas é assim. A vida é assim. (Narrativa de usuários do grupo GAM).

Como observado, o ato prescritivo da medicação realizado pelo médico passa a ser revisto pelos usuários e, desse modo, entendem a fórmula farmacológica como apenas uma das necessidades para sua saúde, sendo até mesmo cogitada a desnecessária adoção dessa prática. Neste âmbito, é interessante notar a relevante preocupação com a dependência ao medicamento prescrito no tratamento dos usuários. 
Ainda como observado, um desafio da reforma psiquiátrica é a assistência em

saúde mental integral, resolutiva e de qualidade. A eficácia das práticas perpassa pela utilização dos medicamentos. Contudo, tal gestão advém de uma baixa criticidade, o que provoca não somente custos crescentes, mas também um novo tipo de exclusão dos pacientes graves, os quais nunca conseguem debater com os profissionais que os tratam o tipo de vida que estão dispostos a levar, e o lugar que desejam dar ao sujeito no ato de prescrever medicamento (CAMPOS et al., 2010). Nessa perspectiva, o sentido cogestivo do grupo GAM apresenta-se nas narrativas com a expressão significativa do empoderamento dos participantes em seus processos terapêuticos. A inovação terapêutica ocorre pela indagação dos usuários sobre seus sofrimentos, transtornos e dificuldades, bem como pela forma adotada por eles e pela equipe de saúde mental na conduta ao equilíbrio psicossocial.

Ao emergir diálogos sobre a conduta terapêutica e a discussão de projetos assistenciais que reconhecem a singularidade e a própria subjetividade dos usuários atendidos, é possível constatar a lateralização das práticas psicossociais no cotidiano dos participantes do grupo.

\section{Construção da sua autonomia: território, abordagens terapêuticas e intersubjetividades}

Nas narrativas, as relações dos usuários convergem nos atributos dos sentidos e significados da convivência com a comunidade, nas práticas terapêuticas e na interação com outros usuários, família e equipe de saúde. Logo, a construção da autonomia está transversalizada nas experiências cotidianas, singulares e subjetivas.

Consoante se percebe, o estigma da doença mental ainda domina nas representações construídas pela sociedade. Evocam-se as pessoas como objetos caracterizados por aquilo que mais querem superar: o transtorno mental. Atribuem-se conotações pejorativas a atitudes corriqueiras que exigem o mínimo respeito possível, quiçá cordialidade. A vivência desse choque relacional emana mais sofrimento quando é preciso aceitar tal situação por conveniência.

No dia a dia, as pessoas nos chamam pelos nossos problemas, chamando de "birita", "alcoólatra", "papudim", "doido véi", de todo nome. Mas não gostamos desta forma de tratamento. $\mathrm{O}$ pior é que às vezes a gente ainda precisa responder às palavras ditas de forma errada. O que não gostamos mesmo de fazer é "não fazer nada", ficar ocioso, não é bom. Também não gostamos de tomar remédio controlado. (Narrativa de usuários do grupo GAM). 

essencial para a construção da autonomia é a inserção em processos produtivos regulares. Emerge, assim, o significado de ociosidade quando no cotidiano dos usuários deixam de ocorrer práticas laborais, atividades físicas e/ou ações que promovam a dinâmica ativa da vida.

Diante do modo objetivante das relações sociais no tocante ao medicamento, os usuários conformam um sentido não prazeroso na sua utilização. Essa situação se intensifica quando alguns fármacos induzem a sintomas/efeitos colaterais. Tais eventos impedem, inclusive, o repouso necessário para o estabelecimento da tranquilidade corporal e mental.

Queríamos parar de tomar remédio. Não gostamos daquele que entorta, o haldol. Tudo com o haldol é complicado, até pra descansar é ruim. Mas os outros, todos fazem bem, sem maiores problemas. Só precisa ter cuidado com a quantidade, pois se tomar muito dá problema. O nome já diz tudo, o remédio é controlado exatamente porque causa efeitos e precisa a gente ter cuidado. $\mathrm{O}$ medo e o nervosismo fazem muito mal pra gente e os remédios que a gente toma deixam a gente mais "assim", melhor, menos assustado. Normalmente, eles nunca afetaram o trabalho. (Narrativa de usuários do grupo GAM).

No entanto, a medicação também pode promover a recuperação da estabilidade e restabelecer soluçôes para os problemas vividos na mente. Para isso, é preciso manter uma constante vigilância na autoadministração do medicamento. Fica evidente a necessidade de cumprir as recomendações médicas e evitar excesso ou interações com fins alterados diante do indicado na bula ou receita.

O remédio faz é tranquilizar. Só se a gente utilizar com outra intenção, por exemplo, o rivotril e o álcool já foram utilizados por mim para sentir uma lombra. Essa mistura dá um efeito alucinógeno e, antigamente, eu fazia isso. Mas isso não é com todo mundo. O médico só passa bons remédios quando a gente diz pra ele a verdade sobre o que se sente. No caso do haldol, às vezes, mesmo dizendo que a gente não quer ou não gosta, é passado do mesmo jeito. A solução nessa situação é fugir, meu irmão. $\mathrm{O}$ CAPS AD e o hospital ajudam muito a gente na nossa saúde, atendendo a gente, dando a medicação, e fazendo novas amizades. A conversa com o médico ajuda a gente se cuidar melhor, porque a gente descobre as curiosidades que a gente tem dúvida. Só com a conversa, a gente já melhora. (Narrativa de usuários do grupo GAM).

Segundo visto, com a melhoria da relação com os profissionais e abertura de espaço de negociação com o médico, é possível utilizar a medicação mais adequada. Esta adequação está relacionada com a indicação medicamentosa para determinado adoecimento e também com a diminuta ocorrência de efeitos colaterais. 
Cabe ressaltar que a restrita formação médica voltada para uma clínica biologizante revela-se no cotidiano dos serviços de saúde por meio das dificuldades de compreensão e conduta em face da complexidade dos eventos vivenciados. Os valores humanos, pouco discutidos na perspectiva científica predominante, denotam baixa resolubilidade perante tais demandas subjetivas entre pacientes e os próprios médicos (ANDRADE; ANDRADE, 2010).

Num sentido diferente, quando as singularidades do usuário não obtêm espaço para a manutenção dialógica sobre sua prescrição medicamentosa, a recorrência na utilização do fármaco promove, além dos efeitos indesejados, um sentimento de revolta e não-adesão à proposta de melhoria do estado psíquico. Para evitar as referidas situações, enfatiza-se a necessidade da interação entre médico e usuário.

Ao dispor da abordagem terapêutica integral, ou seja, ao participar das atividades grupais no CAPS e de consultas individuais em que o diálogo é potencializado, o usuário admite a resolubilidade das conversas e esclarecimentos tomados como discussão nas práticas assistenciais. Tais atitudes remetem ao significado de melhora no estado de saúde pessoal.

Os grupos do CAPS nos ajudam muito na nossa vida. Às vezes, o problema psíquico atrapalha um pouco porque faz com quem a gente esqueça ou coisa assim dos dias de atendimento. Mas se estamos no grupo, sempre é bom para conversar sobre o que se sente, enfim, é uma possibilidade de ser escutado. Nós temos muitas atividades na vida, mas a serenidade que temos em conviver com o outro, no grupo, é importante para falar sobre ela. Enfim, a rede social, os amigos e conhecidos bem como o lazer na vida dependem de cada pessoa, mas sempre é interessante mantê-los. Queremos muito ter um lazer melhor, pois assim evitaríamos coisas ruins para poder manter a saúde. Pois se eu não beber, eu ajudo minha saúde. O tratamento é preciso para a gente se sentir bem. Sem saúde a gente não é nada, não adianta dinheiro, não adianta nada sem saúde. Mas a gente faz tudo e, às vezes, não faz nada para a nossa saúde. Por isso, a alimentação é muito importante para manter a vida saudável. Caminhar e passear também ajuda muito. Muitas vezes, os problemas com álcool impedem ou fazem com que a gente perca o que se tinha alcançado na vida profissional. As experiências no tratamento que a gente tem fazem com que possamos refletir sobre a vida, as dificuldades e situações enfrentadas no dia a dia. A violência hoje em dia está muito presente nas nossas vidas. Sempre que possível, ao vir para o CAPS ainda convidamos outras pessoas para se ajudarem. Às vezes, muita gente não quer vir mesmo sendo para o bem deles, mas se fosse para um bar ou um boteco, num instante estaria por aqui. Mas é isso, sonhar só faz mal para quem não sonha. (Narrativa de usuários do grupo GAM).

Ressaltam-se, ainda, as mudanças ocorridas concomitantente ao uso da medicação como determinantes para a qualidade de vida: alimentação saudável, atividades físicas e abstinência no uso de bebidas alcoólicas. Por tais medidas, 
consiste o entendimento do valor da saúde na existência como um todo e na melhoria dos agravos à saúde mental, especificamente.

É na experiência de vida dos usuários que sobressaem os indicativos para condutas terapêuticas integrais e singulares. $\mathrm{O}$ estresse cotidiano do mundo contemporâneo e os determinantes dessa conjuntura global - como exemplo, a violência - estão permeando a vida de toda a população. Na superação desta condição pelos usuários do CAPS, a comunidade pode também encontrar soluções para seus enfrentamentos e tensões.

A esperança na promoção da saúde mental e nos reflexos dela nas experiências singulares incentiva a adoção de práticas não-medicamentalizadas, e se assim forem, que mantenham a condição física e psicológica ideal para não se tornarem dependentes ou utilizarem de forma abusiva algo indicado para a pretensa melhora no estado de saúde.

Conforme proposto, os caminhos para superação da medicalização devem estar abordados nas seguintes ações: além-consulta médica, intersetoriais, grupais, educativas, políticas, sanitárias, em parceria com instituições culturais, políticas, educativas etc. Tais medidas são essenciais para evitar a medicalização desenfreada que a pura oferta de consultas médicas comumente gera no cotidiano dos serviços de saúde (TESSER, 2006). Nesse incentivo coletivo, as trocas de experiências ocorrem numa intersubjetividade solidária. Recusas ou distanciamentos são tomados como atitudes comuns do processo de vida contemporâneo. Já as subjetividades se expressam nas atitudes de cada participante em conviver melhor com seu tratamento e manter a saúde em estado adequado para a vida em sociedade, de modo autônomo e emancipado.

\section{Gestão autônoma da medicação e atenção psicossocial: tecendo uma rede de cuidados entre os serviços de saúde, familiares e comunidade}

A atenção psicossocial possibilita a assistência em saúde mental dos usuários no SUS, a partir das práticas operadas nos serviços de saúde, nos domicílios e comunidade. Neste âmbito, a cidadania se torna o objeto principal das atividades desenvolvidas para emancipação e autonomia do usuário em seu viver. Desse modo, equipes de saúde, familiares, usuários e familiares compartilham saberes e atitudes voltados para a gestão autônoma da medicação. 
Segundo se percebe, as atividades do grupo GAM facultaram o aprendizado sobre os direitos do usuário do SUS. Pela legislação brasileira, a saúde é um direito de todos e dever do Estado. Sendo assim, os usuários tomam consciência da oferta necessária de serviços para o atendimento das suas demandas e problemas de saúde. O processo de reconhecimento de seus direitos enfatiza os princípios da universalidade, integralidade e equidade da atenção à saúde.

Precisamos nos organizar para buscar nossos direitos enquanto paciente. As dificuldades ainda são muitas, tanto na vida pessoal como no próprio tratamento. As leis do Brasil são muito ruins, não resolvem nada. (Narrativa de usuários do grupo GAM).

Consoante se aprende, as iniquidades apresentadas pelas narrativas convergem na desproporcionalidade entre a oferta e a demanda de serviços de saúde. Tal situação ocasiona um entrave significativo no fluxo de atendimento: o acesso inadequado. A baixa cobertura dos serviços alerta para o descumprimento da legislação que determina a atenção à saúde de modo amplo e resolutivo.

Cabe enfatizar que o desafio de produzir o cuidado em saúde de forma integral é possibilitar a garantia do usuário em ser atendido, os seja, ter acesso pleno e universal para suas necessidades e demandas de saúde apresentadas em toda a rede de serviços e no próprio diálogo singular para com os trabalhadores de saúde. A integralidade começa no processo de trabalho em saúde, no qual às ações multiprofissionais adicionam-se os elementos de vínculo e responsabilização. Daí provém um cuidado a partir da interação de diversos saberes e práticas envolvidas no ato produtivo (FRANCO; MAGALHÃES JR, 2006).

No processo de gestão autônoma da medicação, o usuário é envolvido em práticas de inclusão, isto é, discute seu projeto terapêutico no sentido de autonomizar suas atitudes perante o adoecimento mental. Assim, a abordagem farmacoterápica é relativizada diante da incisiva interrogação do usuário no tocante ao seu tratamento.

O uso do medicamento é quase sempre indicado ou sugerido pelo médico do posto, do CAPS, do hospital. O ruim é que cada vez que a gente é atendida nos postos de saúde é um médico diferente. Ainda bem que existem alguns que atendem de forma diferente e por causa deles é que a gente é encaminhado para o CAPS. Quando a gente conversa com o médico, é possível discutir a dose e o tipo de medicamento mais adequado, como os efeitos, azia, etc. Tem alguns médicos que nos ajudam nessa conversa, sendo bastante atenciosos. Mas normalmente quem não tem tempo é o médico, porque a gente sempre tem tempo pra conversar. Os profissionais dizem que a falta de conversa é mesmo uma realidade e sugerem que pode ocorrer uma mudança partindo da iniciativa do próprio usuário em conversar com o médico sobre a medicação 
melhor, melhor para quem usa, de modo tranquilo, perguntando, tirando dúvidas. (Narrativa de usuários do grupo GAM).

Para tanto, a equipe de saúde, especificamente o médico, atende ao usuário com a premissa de ampliar o horizonte terapêutico e referenciar para a unidade mais especializada em saúde mental - no caso, o CAPS. Como exposto, a dificuldade referida pelos usuários reflete a alta rotatividade entre os médicos que atuam nas unidades de saúde.

Quando a equipe está completa, ou seja, com a presença do médico, a consulta precisa ainda favorecer a conversa entre o usuário e o profissional, no sentido de abordar questões relacionadas à administração correta da medicação e dúvidas sobre indicações, efeitos adversos ou colaterais. Nesse contexto, o fluxo aumentado de pessoas impede a disposição para ampliar a relação dialogada no ato clínico. As consultas ocorrem numa sequência que desfavorece a manutenção da relação terapêutica integral. Embora a necessidade do usuário seja interposta, o médico normalmente não tem tempo para consultar neste formato.

Dificuldades na gestão dos serviços de saúde mental relacionadas à demanda excessiva e precárias condiçôes de trabalho contribuem, ainda, para a baixa permanência de médicos nos Caps. Portanto, a linha do cuidado em saúde mental é prejudicada pela incidência de procedimentos e intervenções no caminhar terapêutico. Assim, em tempo de dificuldades de acesso, o usuário possui um espaço conflituoso para conseguir atendimento na rede de saúde. Tal situação dificulta a elucidação de dúvidas sobre o tratamento, como o uso de medicamentos, horários e formas de apresentação indicadas pelo tratamento adotado.

Temos o direito de fazer exames, receber os remédios gratuitamente e ser atendido nos serviços de saúde. Mas, para ser atendido nos postos de saúde, é preciso chegar muito cedo, algumas vezes, é preciso ir 1, 2 ou 3 vezes para conseguir uma ficha. $\mathrm{O}$ remédio precisa ser tomado na hora certa. A medicação precisa de orientação médica e, se fizer um efeito indesejado, temos o direito de conversar com o médico sobre esse problema. É bom ficar atento na receita. É importante perguntar ao médico se a prescrição mudou ou se é o mesmo remédio prescrito nas consultas passadas, principalmente nos casos de difícil compreensão da letra do prescritor. É um direito do paciente entender sobre a sua medicação. (Narrativa de usuários do grupo GAM).

A narrativa revela que a medicação necessita de orientação médica, no caso de surgimento de reações adversas, em que os usuários se preocupam em retornar para consulta médica, sobretudo quando se trata da difícil grafia. Essas situações 
geram anseios aos usuários e por isso, merecem atenção especial. Desse modo, não somente o médico deve deter as informações e conhecimento sobre os efeitos da medicação, cabendo também à equipe de saúde mental ser detentora do conhecimento para elucidar dúvidas e questionamentos dos usuários. Nessa perspectiva, o usuário torna-se autônomo para discutir amplamente com os profissionais de saúde sobre seu plano terapêutico, assumindo papel de sujeito central na construção de seu tratamento.

No grupo GAM, a autonomia é construída pela discussão dos problemas de saúde. A acessibilidade à informação e a própria capacitação sobre uso de medicamentos de modo racional favorecem a compreensão dos usuários sobre as nas receitas recebidas. Muitas vezes, tais receitas só estão legíveis para quem já está habituado a receber prescriçōes com letra deste ou daquele profissional.

$\mathrm{O}$ atendimento em saúde, no CAPS, por exemplo, é um local que temos boas relações sociais. É importante para o nosso cuidado e para se viver melhor. Os agentes comunitários de saúde participam do nosso cuidado juntamente com a equipe dos postos de saúde. E agora, um local que nos ajuda também é o grupo do GAM, estamos gostando. (Narrativa de usuários do grupo GAM).

Contudo, a rede cuidadora não está se restringe aos serviços de saúde; aliás, pressupōe a articulação com outros instrumentos e organismos sociais como família, religiosidade, enfim, as redes sociais de apoio. Na esfera dessa elaboração do sujeito, a atenção à saúde que se queira e se permita integral não pode se limitar ao espaço terapêutico, ao eixo de comunicabilidade com o usuário; ela passa a admitir as circunscriçôes socioculturais em que este sujeito se insere e se revela. É preciso perceber o cuidado como rede, como uma articulação de outros organismos e redes de apoio (SILVA JUNIOR; ALVES; ALVES, 2005).

Também temos os vizinhos e a família que fazem parte do nosso círculo de amizade. A nossa experiência com as redes sociais é esta: temos amigos, profissionais do CAPS, colegas de trabalho, família, esposa e filhos. E são pessoas maravilhosas para nossa vida. (Narrativa de usuários do grupo GAM).

Nesse sentido, a existência de espaços de discussão sobre a questão dos medicamentos permite aos usuários se encontrar e compartilhar as experiências negativas no tocante à medicação quanto às abordagens terapêuticas. A rede social de cuidados no território se inicia com a participação dos familiares no projeto terapêutico, bem como na integração com os agentes comunitários de saúde, equipes de saúde da família, entidades e comunidade em geral. 


\section{Considerações finais}

Urge a implementação da gestão autônoma da medicação de modo intensificado nas relaçōes terapêuticas operadas nos serviços de saúde do SUS. Tal iniciativa promove uma prática singular e reflexiva que se estrutura nas experiências das pessoas. Por isso, a vivência grupal e a capacitação ativa entre usuários e equipe de saúde indicam melhoria na condição de vida e equilíbrio psicossocial.

Em todo o processo de discussão sobre a medicação, fica evidente que a escuta e o acompanhamento individual - ou seja, a abordagem singular dos usuários - propicia melhoria significativa no estado de saúde mental. Desse modo, é possível ressignificar a utilização precípua do medicamento e interagir com inovaçôes terapêuticas mais voltadas para hábitos de vida saudável. Nesse âmbito, a compreensão consciente e crítica promovida pela troca de experiências entre os usuários desvela coletivamente os direitos garantidos pela legislação ao tratamento em saúde mental. Mas as práticas farmacológicas, voltadas para a medicamentalização do processo de restabelecimento do equilíbrio psíquico, são ponderadas também pelos sentimentos e percepções do usuário. Assim, a autonomia construída pela participação ativa no grupo GAM propicia a reflexão sobre o lugar do tratamento na vida dos usuários, questionando as possibilidades terapêuticas e consolidando o poder de escolher de modo corresponsável as práticas assistenciais mais adequadas para o sofrimento vivenciado.

Consonante com os princípios do SUS, a proposta canadense remete para o desenvolvimento das atividades grupais disparadoras da transformação exigida no campo da saúde mental. Por fim, o controle do tratamento se inverte para o polo usuário numa relação hegemonizada pelo saber técnico. O caminho para a autonomia na medicação é a consolidação dos princípios e diretrizes do SUS e o reconhecimento das intersubjetividades na atenção à saúde e na formulação de pactos intersetoriais no território.

Como se evidencia, com o GAM os usuários motivaram-se para se expressar e, assim, mediante diálogos, os vínculos foram fortalecidos. O fortalecimento do vínculo entre os outros usuários do grupo o configura como unidade - isto é, grupo configura também reflexões e valorização do encontro entre usuários e os profissionais dos CAPS AD e CAPS Geral. Tanto as discussões como as experiências proporcionaram momentos desencadeadores de autonomia dos usuários, no sentido 
de encorajar a diálogo com seu médico sobre a medicação, seus sintomas, propondo inclusive redução do medicamento. Este diálogo foi escutado. ${ }^{1}$

\section{Referências}

AMARANTE, P. Loucos pela vida: a trajetória da reforma psiquiátrica no Brasil. Rio de Janeiro: Fiocruz, 2000.

AMARANTE, P. Saúde mental e atenção psicossocial. Rio de Janeiro: Fiocruz, 2007.

ANDRADE, E.O.; ANDRADE, E.N. A morte iminente, sua comunicação aos pacientes e familiares e o comportamento médico. Rev Bras Clin Med, v.8, p. 46-52, 2010.

AYRES, J.R.C.M. Cuidado e reconstrução das práticas de saúde. Interface Comunic. Saúde, Educ. Rio de Janeiro, v.14, n.8, p.73-91, 2004.

CAMPOS, R.T.O. et al. O. Pesquisa avaliativa de saúde mental: instrumentos para a qualificação da utilização de psicofármacos e formação de recursos humanos. Disponível em: <http://www.fcm.unicamp.br/laboratorios/saude_mental/arquivos/1_novo.pdf>. Acesso em: 21 jan. 2010.

CECÍLIO, L.C.O. As necessidades de saúde como conceito estruturante na luta pela integralidade e eqüidade na atenção em saúde. In: PINHEIRO, R.; MATTOS, R. A. (Org.). Os sentidos da integralidade na atenção e no cuidado à saúde. Rio de Janeiro: IMSUERJ, 2006. p. 115-128.

FERLA, A.A. Participação da População: do Controle sobre os Recursos a uma Produção Estética da Clínica e da Gestão em Saúde. PHYSIS: Rev. Saúde Coletiva, Rio de Janeiro, v.14, n.1, p.85-108, 2004.

FRANCO, T.B.; MAGALHÃES JÚNIOR, H.M.M. Integralidade na assistência à saúde: a organização das linhas do cuidado. In: MERHY, E.E. (Org.). O trabalho em saúde: olhando e experienciando o SUS no cotidiano. São Paulo: Hucitec, 2006. p.125-34.

FURTADO, J.P. Um método construtivista para a avaliação em saúde. Ciência e Saúde Coletiva. Rio de Janeiro, v. 6, n.1, p.165-182, 2001.

KOIFMAN, L. O modelo biomédico e a reformulação do currículo médico da Universidade Federal Fluminense. Hist. cienc. saude-Manguinhos. Rio de Janeiro, v.8, n.1, p. 49-69, 2001. MACIEL, A. Clínica, indeterminação e biopoder. In: Comissão de Direitos Humanos do CRP-RJ. (Org.). Direitos humanos? O que temos a ver com isso? Rio de Janeiro: Conselho Regional de Psicologia, 2007. p.55-62.

ONOCKO-CAMPOS, R., FURTADO, J.P., PASSOS, E., BENEVIDES, R. Pesquisa avaliativa em saúde mental. Desenho participativo e efeitos da narratividade. São Paulo: Hucitec, 2008 p.428. 
PELBART, P.P. Elementos para uma cartografia da grupalidade. Disponível em: <http:// www.rizoma.net/ interna.php?id=189\&secao=mutação>. Acesso em: 12 fev. 2011.

RICOUER, P. Do texto à ação: ensaios de hermenêutica II. Portugal: Rés, 1991.

SILVA JUNIOR, A.G.; ALVES, C.A.; ALVES, M.G.M. Entre tramas e redes: cuidado e integralidade. In: PINHEIRO, R.; MATTOS, R.A. (Org.). Construção social da demanda: direito à saúde, trabalho em equipe, participação e espaços públicos. Rio de Janeiro: Cepesc, 2005. p. 77-89.

SOARES, J.C.R. de S.; CAMARGO JR., K.R. A autonomia do paciente no processo terapêutico como valor para a saúde. Interface. Botucatu, v. 11, n. 21, abr.2007. Disponível em: <http://www.scielo.br/scielo. php?script=sci_arttext\&pid=S1414$32832007000100007 \& \operatorname{lng}=$ pt\&nrm=iso $>$. Acesso em: 21 jan. 2011.

TESSER, C.D. Medicalização social (I): o excessivo sucesso do epistemicídio moderno na saúde. Interface. Botucatu, v. 10, n. 19, p. 61-76, 2006.

\section{Nota}

${ }^{1}$ M.S. Bessa Jorge participou da concepção e planejamento do projeto, obtenção de dados, análise e interpretação dos resultados e elaboração do rascunho do manuscrito. R. Onocko-Campos participou da concepção e planejamento do projeto, análise e interpretação dos resultados e elaboração do rascunho do manuscrito. A.G. Alves Pinto participou da obtenção de dados, análise e interpretação dos resultados e elaboração do rascunho do manuscrito. M.G. Ferreira Vasconcelos participou da obtenção de dados, análise e interpretação dos resultados e elaboração do rascunho do manuscrito. 


\section{Abstract}

Experiments with autonomous management of medication: narrative of mental health users in focus group meeting in psychosocial care centers The study aimed to analyze the feelings experienced by users of the Center for Psychosocial Care in developing the group for Autonomous Management of Medication (AMM). It uses qualitative research within a critical perspective that carries the experience of participating in the operative AMM group. It was conducted at the General Center for Psychosocial Care (CAPS) and Alcohol and other Drugs (AD) in the city of Maracanau, state of Ceara, Brazil. The participants were 13 users of General and Ad CAPS of that city. The technique of narratives' collection consisted of three groups based in the narrative analysis and hermeneutics. According to the narratives, throughout the discussion process on the medication, it is evident the importance of listening and coaching. The unique approach of users allowed significant improvement in health status and understanding of mental illness. Thus, it is possible to reframe the specific use of the drug and interact with therapeutic innovations that focus more on healthy lifestyle habits.

Key words: mental health; center of psychosocial attention; autonomous management of medication. 